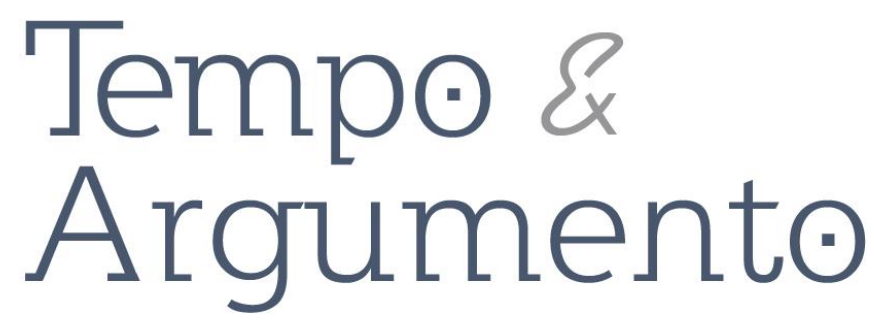

\title{
Infâncias e Direitos no tempo presente: uma entrevista com Carla Villalta
}

\section{Entrevistada}

Carla Villalta é licenciada em Ciências Antropológicas e doutora em Antropologia pela Facultad de Filosofia y Letras da Universidad de Buenos Aires (UBA), instituição em que atua como professora titular e cocoordenadora da equipe de investigação em Antropologia Política e Jurídica. É pesquisadora junto ao Consejo Nacional de Investigaciones Cientificas y Tecnicas da Argentina (Conicet), atualmente faz parte do Programa Ciencia y Justicia, parceria desta instituição com o Poder Judiciário e o Ministerio Público de la Defensa. Seus temas de investigação têm se concentrado no aparato jurídico-burocrático destinado à infância pobre e suas famílias e em particular sobre os procedimentos utilizados para a apropriação criminosa de crianças durante a última ditadura militar argentina.

Entrevista concedida em 04 de fevereiro de 2019, na Univerdidade de Buenos Aires.

\section{Entrevistadora}

Camila Serafim Daminelli

Doutoranda em História pela Universidade do Estado de Santa Catarina (UDESC).

Florianópolis - SC - Brasil

camis.hst@gmail.com orcid.org/0000-0003-1893-1543

\section{Para citar esta entrevista:}

VILLALTA, Carla. Infâncias e Direitos no tempo presente: uma entrevista com Carla Villalta. [Entrevista realizada em 04 de fevereiro de 2019]. Revista Tempo e Argumento, Florianópolis, v. 11, n. 27, p. 494 - 508, maio/ago. 2019. Entrevistadora: Camila Serafim Daminelli. 
Tempo e Argumento: Para iniciar y situar la conversación, ¿sería posible esbozar una definición contemporánea de derechos humanos, así como un breve curso histórico sobre el tema?

Carla Villalta: La idea de que existen determinados derechos que corresponden a todos los seres humanos es, claro está, una idea occidental y moderna que se basa en otra noción -también occidental y moderna- la de igualdad. Sobre la base de esta última se va a construir la idea de los "derechos humanos" como derechos universales e inalienables que los estados deben respetar y garantizar. No obstante, esta idea también tiene su historicidad. Por ejemplo, en el siglo XVIII, en la primera formulación de los Derechos del Hombre, esa igualdad (la idea de que los hombres nacen libres e iguales y son iguales ante la ley) englobaba únicamente, como es sabido, a los varones blancos, en tanto el individuo ejemplar estaba calcado en sus rasgos. De hecho, como ha planteado Joan Scott, las mujeres no entrábamos en esa condición, no formábamos parte de ese "individuo abstracto" construido como un ideal, que era definido por un determinado conjunto de trazos de tendencias psicológicas invariantes y que era parámetro de racionalidad y de sentido moral. Ahora bien, la ampliación de esa noción, es decir que actualmente abarque no tan solo a ese individuo modélico, fue el resultado de diversas luchas sociales y de un largo proceso histórico. En efecto, en su versión contemporánea, la noción de igualdad va a ser revisada, complejizada y también expandida, y así el "individuo político" dejará de ser solo el varón blanco. Además, si en sus primeras formulaciones los derechos humanos eran principalmente los individuales, políticos y civiles -en los que primaba la idea de defenderse del Estado-, a partir de esas diversas luchas otros "derechos" van a ser construidos como tales, y lo que comenzará a tematizarse, de muy distintas maneras, es que los ciudadanos también tienen derechos a ser protegidos por el Estado. La distinción entre derechos de primera y de segunda generación da cuenta de esa redefinición y ampliación, ya que también se construirán como derechos los económicos, sociales y culturales. Además, en el escenario internacional la doctrina internacional de los derechos humanos tiene un punto de inflexión en 1948, ya que la Declaración Universal de los Derechos Humanos de ese año, teñida de la preocupación y los debates internacionales del clima de posguerra y de la verificación de los estragos 
producidos por el régimen nazi, va a estar acompañada por la construcción de una nueva estructura internacional. El Ilamado "sistema ONU” confirió a los derechos humanos otra ambición de materialidad, ya que a partir de ese momento histórico no solo se producirán declaraciones sino también otros documentos, como las convenciones internacionales, que obligan a los Estados firmantes a su cumplimiento. No obstante, como sabemos y como en estos días estamos tristemente experimentando, se trata de un campo de relaciones de fuerza en el que las potencias que más violan los derechos humanos en muchas ocasiones hacen caso omiso a las recomendaciones que pudieran emanar de este sistema. Sin embargo, me gustaría señalar dos cosas. Por un lado, que es necesario tener en cuenta que aun actualmente la noción de derechos humanos es tributaria de esa declaración que estipuló como principios básicos de los derechos humanos su universalidad, interdependencia e indivisibilidad, y también los principios de igualdad y no discriminación. Estos principios han servido a distintas luchas y fueron un recurso eficiente y legítimo para diferentes demandas que tuvieron lugar durante el transcurso del siglo XX. Particularmente, en nuestra región han sido una poderosa herramienta para cuestionar, denunciar y juzgar los crímenes de lesa humanidad cometidos por las dictaduras militares. $\mathrm{Y}$ principalmente por ello entiendo yo se han convertido a través de la lucha política en un lenguaje legítimo para expresar diversos tipos de demandas y reclamos al Estado. Por otro lado, lo que también quiero enfatizar es que los derechos lejos están de tener un pretendido "mana" o una especie de fuerza mágica que por sí sola conduce a su cumplimiento o respeto. Justamente atender a la historicidad de los derechos humanos nos permite observar su politicidad y también tener en cuenta que pueden servir a fines diversos.

Tempo e Argumento: ¿Podría ejemplificar tal diversidad en el uso o apropiación del discurso de derechos humanos?

Carla Villalta: Como ha sido señalado por diversos autores, el discurso de derechos humanos tanto ha servido para extender bajo la apariencia de universalidad una mirada occidentalizante de la sociedad, como también para que en diversos lugares y contextos distintos grupos sociales puedan hacer audibles, legibles y legítimos sus 
reclamos. En este sentido, también me parece importante tener en cuenta que existen diferentes perspectivas y visiones para pensar los derechos humanos y los procesos en los que han tenido un rol protagónico. Por un lado, una visión legalnormativa, desde la cual los derechos son considerados como atributos universales y atemporales. Ese tipo de visión refuerza una mirada ontológica de los derechos que se preocupa más por lo que los derechos son o no son, en tanto los considera como una suerte de "cosa", como una especie de talismán con efectos mágicos y duraderos. Y así, desde esta visión parece reforzarse una idea fetichista de los derechos que no permite ver, que esconde, los procesos y relaciones que los han constituido y que en todo caso los han conformado como un objeto preciado. Por otro lado, desde un abordaje socio-antropológico de los derechos, en lugar de aquella versión ontológica, se ha propuesto una mirada relacional, situacional e histórica que, en lugar de ver a los derechos como atributos universales y atemporales o bien de preguntarse por lo que los derechos "son", permita interrogarse acerca de sus significados, usos y valores. En otras palabras, en lugar de inquirir por la esencia de los derechos o incluso de estar preocupados, como desde una visión normativa suele suceder, únicamente por si se respetan o no se respetan los derechos humanos, desde esta perspectiva -que es a mi entender la más fructífera- se trata de contextualizar y politizar aquellos derechos considerados universales, a partir de estudiar las apropiaciones y significados socialmente construidos sobre derechos humanos, esto es, se trata de estudiar la práctica de los derechos humanos. De esta manera, si en la teoría legal los derechos humanos son universales -y ello tanto puede constituir un auspicioso horizonte como también tener un reverso coactivo y uniformizante-, el análisis de la práctica concreta de las relaciones sociales que los constituyen en cada contexto y que les dan sentido nos permite analizarlos como producciones históricas y culturales imbricadas en relaciones de poder, cuyos efectos no están fijados de antemano, al contrario, pueden ser inesperados e imprevisibles.

Tempo e Argumento: Cuando se cumplen 70 años de la Declaración Universal de los Derechos Humanos, ¿cuáles serían las debilidades que se evidencian en la actualidad a cerca de los derechos enunciados en esa declaración? 
Carla Villalta: Si pensamos en el acceso efectivo al goce de los derechos enunciados en esa Declaración, las fragilidades son numerosas. Principalmente en nuestra región, podemos observar la persistencia de enormes inequidades, de procesos de desigualdad social que restringen sobremanera el derecho a un nivel de vida adecuado que asegure vivienda, salud, eduación, entre otros bienes considerados básicos que hacen al bienestar de las personas y que están enumerados en esa Declaración, así como en los Pactos que a posteriori fueron adoptados por las Naciones Unidas. También podemos verificar importantes déficits en lo que concierne a la prohibición de tratos o penas crueles o degradantes, o bien la misma situación puede verificarse en relación con la garantía de los derechos relativos a la presunción de inocencia y la defensa técnica y material de quienes son acusados de cometer un delito. Para advertir esto, no hace falta más que visitar una cárcel o conocer las prácticas policiales cotidianas que son desplegadas en determinados territorios y en relación con específicos grupos sociales, entre ellos, por ejemplo, los adolescentes y jóvenes varones de barrios populares. No obstante, si miramos estos últimos 70 años podremos ver que la formulación de una retórica de derechos también ha sido convertida en una potente clave de lectura que ha permitido dotar de inteligibilidad a distintos problemas sociales, y así ha permitido tematizar y visibilizar determinadas situaciones de injusticia que desde otras claves de lectura habían sido conceptualizadas como asuntos propios de la filantropía o de la ayuda social, o bien se habían justificado desde un rigorismo punitivo y estigmatizante de aquel que es construido como un "otro". Asimismo, que los derechos puedan ser exigidos ha constituido y constituye una importante herramienta para diversos reclamos y para el activismo legal y político que ha batallado por extender el acceso a derechos para distintas poblaciones y grupos sociales. Ello, claro está, trajo aparejado una serie de dilemas y paradojas, en tanto en algunos casos, como ya he señalado el discurso centrado en derechos, traduce una visión no solo occidental sino también noratlántica respecto de determinados temas, lo que puede llevar a desconocer o a desvalorizar dinámicas y valores locales. Sin embargo, no creo que los derechos tengan un tránsito unilineal, por ejemplo de norte a sur, y solamente sirvan para imponer una visión hegemónica. Esta interpretación solo deja en un lugar de pasividad a nuestros países y no permite observar que el vigoroso movimiento de derechos humanos que ha surgido en muchos de nuestros países 
también ha contribuido no solo a fijar determinados estándares y a construir derechos, sino que también diversos grupos sociales han "usado" estratégicamente el lenguaje de derechos para visibilizar y denunciar determinadas situaciones de injusticia.

Tempo e Argumento: En el panorama actual, con el ascenso de movimientos de derecha y extrema derecha a nivel mundial, ¿cuáles son las amenazas en el campo de los derechos conquistados y de los que aún están por consolidarse?

Carla Villalta: El momento actual es sumamente preocupante ya que pareciera que incluso los acuerdos y consensos más básicos en torno al respeto a la dignidad humana, al trato no discriminatorio y a la igualdad en el mejor y más amplio sentido del término están amenazados y han sido cuestionados públicamente. Es más, como en Brasil se ha podido verificar, en estos momentos no solo esos valores básicos están siendo relativizados o cuestionados, sino también se alientan y exacerban valores antagónicos a aquellos propios de un paradigma de derechos. Así no solo se ponen en duda los valores de la no discriminación, el trato humano, la no violencia y la libertad de expresión, sino también se promueven abiertamente la violencia y el trato discriminatorio y estigmatizante. Por ejemplo, en mi país, desde las máximas autoridades se ha respaldado a personal policial que ha incurrido en casos de "gatillo fácil”, esto es, de ejecuciones de jóvenes, o bien se defiende el "derecho" a portar armas. Además de eso, en esta escalada de derechización del discurso público e institucional, se ha dicho que no tiene sentido construir universidades en determinadas zonas porque los pobres no van a la universidad, o bien se promueve cada vez más insistentemente la baja de la edad de punibilidad. Todo esto en un escenario de pérdida del empleo, de endeudamiento creciente y de empeoramiento de todos los indicadores sociales que augura un escenario bastante sombrío. Este momento, lo que nos permite ver es justamente que los derechos no tienen una suerte de mana o de fuerza mágica, como planteaba recién. La conquista de "derechos" siempre es inestable y puede estar amenazada, principalmente porque el consenso sobre determinados estándares mínimos (por ejemplo, que todos los niños y niñas tienen derecho a recibir educación, o bien que no se debe reprimir la protesta social) es fruto de disputas políticas en las que se enfrentan diferentes 
ideas y concepciones sobre el estado, la sociedad, la política, la desigualdad y el conflicto. $Y$ paradójicamente en algunos casos sucede que aun cuando las que se defienden son concepciones antagónicas a un paradigma o enfoque de derechos, los actores políticos que las defienden recurren al "lenguaje de derechos" para legitimarse. Por ejemplo, en el caso que recién mencionaba respecto del "derecho a portar armas" o como se ha escuchado en mi país en ocasión de los debates sobre la despenalización del aborto, el "derecho de los nonatos", para restringir y cercenar el derecho de las mujeres a decidir sobre su propio cuerpo.

Tempo e Argumento: La cuestión de los derechos es una importante guía para la producción de las Ciencias Humanas y Sociales relacionadas con la niñez y la juventud. ¿Cómo ha sido su inserción en este campo de estudios?

Carla Villalta: La cuestión de los derechos de niños, niñas y adolescentes, y la particular recepción que en nuestros países tuvo la Convención de los Derechos del Niño aprobada por la Asamblea de Naciones Unidas hace 30 años, motorizó una serie de trabajos en el campo de las ciencias sociales y humanidades. Esto originó estudios muy interesantes y estimulantes para problematizar las maneras en que la infancia, y sobre todo la infancia pobre, fue conceptualizada y administrada por parte del Estado y distintos tipos de organismos y organizaciones que fueron expandiéndose durante el siglo XX con el propósito de proteger y vigilar a los niños y niñas que estaban, según las valoraciones de cada época, en una situación de peligro o abandono. Mi inserción en este campo de estudios se originó a partir del interés que me produjo esta temática al comenzar a trabajar en un organismo del gobierno local de la Ciudad de Buenos Aires de defensa de los derechos de niños, niñas y adolescentes. Estaba compuesto principalmente por abogadas que eran activistas muy comprometidas con la defensa del "nuevo paradigma", inspirado en la Convención de los Derechos del Niño, y que bregaban por distintos cambios en el sistema judicial destinado a la minoridad. A partir del trabajo en este organismo, empecé no solo a interesarme sino también a conmoverme con esta temática y con una historia plagada de mucha arbitrariedad y discrecionalidad, de mucho clasismo revestido de una retórica de hacer el bien, de discusos moralizantes y subestimadores de las capacidades de aquellos sobre los que se intervenía. Todo 
ello me llevó a interesarme en primer lugar por la justicia de menores y por el trato que recibían en ella los niños, niñas, adolescentes y sus familias. Un tratamiento que en aquellos años, fines de la década de los '90, estaba regido aun por la facultad de la "tutela estatal" que posibilitaba que jueces y otros funcionarios públicos desplegaran ese trato minorizante sobre los niños y familias sobre los que intervenían.

Tempo e Argumento: ¿Cómo se ve, a nivel jurídico y social, los derechos de los niños, niñas y adolescentes, especialmente en América Latina, a lo largo del siglo XX?

Carla Villalta: Creo que a lo largo del siglo XX en América Latina hubo una producción muy importante en relación con la defensa y garantía de los derechos de los niños, niñas y adolescentes. De hecho, desde muy tempranamente en nuestra región, distintos actores se comprometieron y trabajaron arduamente para lograr sancionar legislaciones de defensa de los derechos de niños y niñas que obligaran a los estados a cumplir con determinadas prestaciones básicas, relativas a la salud, la educación y la asistencia social, y que, entre otras cosas, por ejemplo, prohibieran el trabajo infantil. Esto se verificó fundamentalmente en el Cono Sur, donde el discurso higienista de principios de siglo puso a la infancia en un lugar central, ya que era la esperanza de porvenir y además era usada como una metáfora del continente. Los estudios sobre los Congresos Panamericanos del Niño y sobre el Instituto Interamericano del Niño, la Niña y los Adolescentes, demuestran cómo a partir de esa preocupación por el porvenir, esos actores impulsaron distintas iniciativas que construyeron a la protección de la infancia como un problema público con distintos grados de visibilización en nuestros países. De esa manera, podemos observar que, al menos formalmente, en la región existió una preocupación por el bienestar de la infancia que se tradujo en la sanción de leyes específicas, en la creación de distintas instituciones que se dedicaron a la protección de la niñez, y que también implicó la aparición y consolidación de distintos saberes en relación con los niños. No obstante, también durante el siglo XX, en nombre del "bienestar del menor", o de manera más actual en nombre del "interés superior del niño", se desarrollaron distintas medidas que se dirigieron a culpabilizar y/o a incapacitar a aquellos que aparecen como los responsables primarios de esos niños, 
sus padres, pero en especial sus madres. Esto es, la protección de la infancia fue en muchos casos la piedra de toque para destituir a padres y madres de su calidad de tales, ya que desde una lente individualista e individualizante de los problemas sociales los recortaba -y en muchos casos aún lo sigue haciendo- como los primeros responsables por la vulneración de los derechos de sus hijos. Esto aún hoy se verifica y se observa con más nitidez justamente en estos momentos en que la ascensión de movimientos de derecha en los gobiernos de nuestros países postulan una mirada individualista e individualizante de los problemas sociales, que se despliega y refuerza en una visión meritocrática. Y así se hace recaer exclusivamente en la capacidad de los sujetos, o en la falta de ella, las razones de su éxitos o fracasos. Desde esta perspectiva, esto es, desde una visión reduccionista, ontológica y moralizante, los derechos de los niños y niñas pueden ser construidos como antagónicos a los derechos de sus padres y madres, recreando una falsa y dicotómica visión.

Tempo e Argumento: ¿Es posible hablar en un "progreso" de estos derechos en relación con los procesos experimentados en América Latina?

Carla Villalta: En verdad, no me parece correcto hablar en términos de progreso o de evolución. En cambio, considero pertinente hablar de conquistas y logros, básicamente porque pensar así nos lleva a analizar los procesos socio-históricos a través de los cuales los derechos se fueron expandiendo y ampliando, o bien limitando y restringiendo, esto es, como vengo planteando, nos permite pensar los derechos en términos de luchas y de disputas. Y ello nos permite indagar cuáles fueron los actores que participaron (y participan) en esas contiendas y qué posturas ideológicas y qué concepciones de infancia, de familia, pero también de sociedad y/o de estado sustentan. En ese sentido, creo que los procesos que se han vivido en América Latina, más allá de sus enormes y persistentes déficits, es decir, más allá de ser procesos que aún manifiestan un alto grado de fragilidad en relación con esas conquistas, son muy importantes en tanto permiten observar que en nuestros países -aun con sus particularidades y singularidades contextuales- han existido y existen construcciones colectivas de envergadura y un interesante activismo en defensa de los derechos de los niños, niñas y adolescentes. Un activismo nutrido 
por militantes de distintos tipos de organizaciones, por especialistas y expertos, por juristas, por trabajadores y trabajadoras de las instituciones destinadas a la infancia, e incluso por niños, niñas y adolescentes, que ha permitido modificar algunos de los aspectos más violatorios de derechos que detentaba la intervención estatal sobre la infancia y la adolescencia, y construir distintas alternativas y formas de abordaje. $Y$ estos tipos de alternativas permitieron contrarrestar, al menos en parte, o bien permitieron visibilizar y cuestionar algunos de los mecanismos por los cuales operan procesos de diferenciación social (esto es, diferente tratamiento según la posición social) que se traman en y reproducen la desigualdad social como rasgo persistente en nuestros países.

Tempo e Argumento: En su obra, el tema de la niñez y adolescencia está conectado al derecho a la verdad y a las "apropiaciones criminales" que ocurrieron durante la última dictadura militar argentina. ¿Cuáles serían las especificidades de esta experiencia en el ámbito de los derechos, o su infracción?

Carla Villalta: Mis trabajos sobre la apropiación criminal de niños desarrollada por la última dictadura militar en la Argentina se originaron a partir de un interrogante que, de una forma u otra, recorrió a toda mi generación, la pregunta acerca de cómo fue posible que sucedieran hechos tan aberrantes. En este sentido, la indagación que emprendí estuvo presidida por el intento de comprender el cómo de esos hechos. Esto es, por el interés de conocer y procurar explicar cuáles habían sido los procedimientos usados para llevar a cabo la apropiación de niños y cuáles habían sido sus condiciones sociales de posibilidad. Por eso, comenzar a indagar sobre este tema me llevó a analizar cuáles fueron los procedimientos concretos que se usaron y también las singularidades que revistieron esos hechos criminales que se inscribieron en una política represiva extrema y fueron parte de un plan políticoideológico que se intentó implantar en la sociedad argentina, pero también paralelamente me llevó a realizar una reconstrucción genealógica de diferentes dispositivos jurídico-burocráticos y de las rutinas de distintas instituciones destinadas a la infancia, por las que eventualmente transitaron muchos de los niños y niñas cuyos padres y madres habían sido secuestrados y desaparecidos. Muchos de esos niños y niñas fueron institucionalizados o encaminados a la adopción y de 
esa manera les fue sustituida su identidad, ya que previamente un juez de menores había considerado que eran "menores abandonados". Asimismo, al analizar el campo de significados que rodeaba a las prácticas institucionales y sociales en relación con la infancia pobre es posible identificar la persistencia de una actitud salvacionista por la cual quienes se encontraban investidos de autoridad pasaban a decidir sobre el destino de niños, niñas y familias, ya que el fin último era la salvación de estos. Una actitud que entiendo también se hizo presente en las prácticas y en el discurso militar que intentó justificar y difuminar el carácter criminal de esas apropiaciones. Por eso creo que el hecho de la apropiación criminal de niños y niñas durante la dictadura, hecho que fue ciertamente excepcional, nos permite observar que fue tramado a partir de normalidades socialmente admitidas por las cuales, por ejemplo, se veía como positivo que un menor "abandonado" sea encaminado a la adopción sin muchas averiguaciones respecto de su familia de origen, o bien se inscribieran como propios a niños que no lo eran, en tanto lo que justificaba a esas prácticas era la pretendida salvación de esos niños, quienes siguiendo este razonamiento- estarían mejor en el seno de otras familias que los pudieran cuidar y educar como se debía. Este tipo de nociones y valoraciones en el contexto del terrorismo de estado fueron reutilizadas por el discurso militar para demonizar a quienes se clasificaba como "padres subversivos" y, por tanto, "sin derecho a criar a sus hijos". En tal sentido, en nuestra sociedad la labor de Abuelas de Plaza de Mayo fue central para poder denunciar la atrocidad de esos crímenes y también para demostrar que los mismos se habían tramado en esas creencias y normalidades admitidas. De hecho, tal como ellas han contado, durante la época de la dictadura, pero también en los primeros años de democracia, muchos actores institucionales -entre ellos jueces de menores- les decían que no buscaran más a sus nietos o nietas ya que se encontraban con "buenas familias", que los mandaba a colegios privados y los educaba con amor. La lucha de Abuelas de Plaza de Mayo y en general del movimiento de derechos humanos en la Argentina posibilitó así no solo denunciar y emprender el juzgamiento de esos crímenes, sino también demostrar que los mismos se asentaron en tramas de relaciones preexistentes de las que participaron distintos tipos de actores. 
Tempo e Argumento: ¿De qué manera la sociedad argentina se relaciona con la experiencia de las "apropiaciones criminales" vinculadas al terrorismo de Estado, y qué lugar tiene hoy este tema, en los debates sobre los derechos sociales y las políticas dirigidas a niños, niñas y adolescentes?

Carla Villalta: Creo que una de las cuestiones centrales que ha posibilitado la lucha de las Abuelas de Plaza de Mayo en relación con los derechos de los niños, niñas y adolescentes es la revalorización de la verdad y, por tanto, de tratar como sujetos y no como objetos o como cosas a los niños y niñas. En ese sentido, creo que como sociedad debemos mucho a la lucha de las Abuelas en tanto su primera lección ha sido este señalamiento ético. $\mathrm{Y}$, como tal, yo creo que ha permeado de diferentes maneras a las instituciones dedicadas a la infancia y que también ha atravesado aunque ese no haya sido el objetivo inicial de la lucha de las Abuelas- a los debates sobre los derechos de niñas, niños y adolescentes que han tenido lugar desde la posdictadura hasta ahora. Justamente, hace muy pocos días en mi país, a raíz de un indignante caso de trato inhumano en el que a una niña que estaba embarazada fruto de una violación le practicaron una cesárea en la semana 24 de gestación, en lugar de haber realizado una interrupción del embarazo semanas antes, cuando lo solicitó, desde algunos sectores se recordó ese señalamiento ético de las Abuelas. En este caso, una vez que se conoció que a la niña le habían sometido a una cesárea y la recién nacida se encontraba en neonatología, el gobernador de la provincia de Jujuy declaró a los medios que la bebé sería dada en adopción a "una importante familia". Esta idea cargada de un importante contenido clasista que procura basarse en el razonamiento de que el fin último -que esos bebés sean criados por familias importantes- justifica cualquier medio empleado y difumina el carácter oprobioso de determinados hechos forma parte del señalamiento ético de las Abuelas y de la enorme potencialidad de su lucha. Además de ello, claro está, el derecho a la identidad ha sido una construcción central, producto de la lucha y el activismo de las Abuelas de Plaza de Mayo. Tanto así que los artículos 7 y 8 de la Convención de los Derechos del Niño, que postulan y resguardan ese derecho, son conocidos mundialmente como los artículos argentinos. 
Tempo e Argumento: ¿Qué, en su opinión, es la fuerza de la retórica de los derechos cuando se aplica a los niños, niñas y adolescentes?

Carla Villalta: En Argentina, aunque entiendo que en otros países de la región también, esa fuerza retórica se debió a que el enfoque de derechos sirvió para cuestionar e impugnar prácticas recurrentes y habituales en el circuito de instituciones destinadas a la infancia pobre. Esto fue así al menos inicialmente, es decir, en los años cercanos a la aprobación de la Convención de los Derechos del Niño, distintos activistas construyeron una potente dicotomía que oponía al "paradigma de la protección integral”, basado en un lenguaje de derechos, y al "paradigma de la situación irregular o del Patronato", basado en las antiguas leyes de la minoridad que conceptualizaba a los niños no como "sujetos", se sostenía, sino, como “objetos” de protección y de tutela. Creo que la fuerza retórica que tuvo proviene en gran medida de la forma en que se construyó y se comunicó esta oposición. De hecho, la Convención fue presentada como un hito, como un parteaguas en la historia del tratamiento de la infancia; en otras palabras, como un instrumento absolutamente innovador y novedoso que venía a cambiar radicalmente la forma de pensar y de tratar a los niños, las niñas y los adolescentes. Ello generó grandes niveles de consenso, al menos en un plano discursivo, y el "interés superior del niño" fue una fórmula que se expandió rápidamente, aunque en ocasiones pudo servir más a un "cambio de etiquetas" que a una transformación profunda de prácticas y sentidos. Por ello, creo que, si bien esa construcción fue efectiva, en tanto posibilitó cuestionar muchos de los aspectos más violatorios de derechos que eran comunes en las instituciones de la minoridad (es decir, en los grandes institutos y hogares de menores, en los juzgados, en las comisarías), terminó haciendo foco fundamentalmente en las leyes y en los jueces como responsables de esas violaciones de derechos, y así consolidó una interpretación bastante reduccionista y limitante del problema. De esa manera, no permitió cuestionar o visibilizar aspectos y sentidos que, al encontrarse sumamente naturalizados en relación con la infancia y la familia, constituían, y continúan constituyendo, condiciones para la reproducción de prácticas discriminatorias, clasistas y estigmatizantes. 
Tempo e Argumento: Por último, aún acerca de la Doctrina de Protección Integral por la Convención de los Derechos del Niño, de 1989, a raíz de lo que ya había sido proclamado por la Declaración de los Derechos del Niño, en 1959. ¿En qué sentido esta directriz constituye la marca fundamental de un nuevo momento, la "edad de los derechos"? En el plan de las prácticas, ¿hasta qué punto esta doctrina sigue siendo un horizonte en busca de consolidarse?

Carla Villalta: En verdad, como recién mencionaba, creo que la idea de un marco fundante o de un hito ha sido una construcción política que acompañó a la propagación de la Convención en nuestros países y que, como tal, fue potente porque fue sostenida por distintos tipos de activistas que eran muy críticos a las prácticas y rutinas de las instituciones que tradicionalmente se habían encargado de la protección y de la vigilancia de la infancia pobre. En ese sentido, en el plano simbólico, podemos hablar del comienzo de una "nueva era". Pero en verdad si realizamos una genealogía de los derechos de los niños, podremos observar que a la Convención la precedieron no solo otros tratados, que desde las primeras décadas del siglo XX estipularon que los niños eran poseedores y titulares de derechos, sino también podremos observar que muchos de los aspectos que tematizan tanto la Convención como el discurso de los especialistas y expertos que acompañaron la difusión de este instrumento de derechos humanos en nuestra región ya habían sido enunciados y debatidos en años previos a la elaboración de la Convención. Ello nos permite ponderar y poner en perspectiva una suerte de "ineditismo" que rodea muchas veces a las propuestas que se realizan en este campo de intervenciones y de políticas. Y también nos permite tener una comprensión más compleja de los procesos sociales e históricos de transformación y cambio que permita distanciarse tanto de una mirada ingenua, o bien de una visión tecnocrática sobre los derechos. Este tipo de visión parece basarse en la idea de que el enfoque de derechos es una suerte de receta que los actores deben aplicar sea cual fuere el contexto sociohistórico y político en el que esos derechos se deban materializar. De allí que este tipo de visión permita hacer coincidir por ejemplo los derechos con un ideario neoliberal, ya que desde esa clave de lectura se privilegia una visión atomista e individualizada de los "derechos". Así también, extremando este razonamiento, se llega a pensar que si los derechos no se cumplen o no se respetan es porque 
nuestras sociedades -como plantea Adriana Vianna- no se han modernizado lo suficiente como para honrar esa legislación "tan avanzada". Ahora bien, en relación con el cumplimiento o la materialización de los derechos, creo que en estos años el proceso de su institucionalización ha producido una serie de importantes transformaciones y ha tenido diferentes efectos. Es decir, ese proceso del que participaron muchos y muy diferentes actores no ha sido inocuo ni tampoco podemos decir que no ha tenido distintas y variadas consecuencias. En efecto, diferentes prácticas se han modificado, algunas categorías directamente han sido desechadas, otros sentidos han emergido. Ahora bien, es claro también que un enfoque de derechos es esencialmente un horizonte que nortea prácticas y sentidos, y fundamentalmente formas de interpretar conflictos y problemas sociales, y estas formas de interpretación redundaran, o no, en la posibilidad de articular acciones políticas que permitan generar las condiciones materiales que posibiliten la garantía de derechos. Los derechos escritos en un papel son importantes, pero nunca suficientes. En otras palabras, si no están acompañados de acciones políticas que permitan materializar o al menos alcanzar mayores niveles de igualdad de oportunidades para todos los niños y todas las niñas, los derechos solo son una abstracción.

Universidade do Estado de Santa Catarina - UDESC

Programa de Pós-Graduação em História - PPGH

Revista Tempo e Argumento

Volume 11 - Número 27 - Ano 2019 tempoeargumento@gmail.com 